\title{
Seismic resistance of earth construction in Portugal
}

\author{
Maria Idália Gomes ${ }^{\mathrm{a}}$, Mário Lopes ${ }^{\mathrm{b}}$, Jorge de Brito ${ }^{\mathrm{b}, *}$ \\ a Department of Civil Engineering, Instituto Superior de Engenharia de Lisboa, Polytechnic Institute of Lisbon, Rua Conselheiro Emídio Navarro, 1, 1959-007, Lisbon, Portugal \\ ${ }^{\mathrm{b}}$ Department of Civil Engineering and Architecture, Instituto Superior Técnico, Technical University of Lisbon, Av. Rovisco Pais, 1049-001, Lisbon, Portugal
}

\section{A R T I C L E I N F O}

\section{Article history:}

Received 16 July 2010

Received in revised form

22 November 2010

Accepted 1 December 2010

Available online 30 December 2010

\section{Keywords:}

Rammed earth

Seismic behaviour

Stress analysis

\begin{abstract}
A B S T R A C T
This paper presents an assessment of the potential seismic performance of new earth construction in Portugal. Results of a parametric study on a properly designed rammed earth construction, considering several strengthening solutions, are presented and discussed. It is concluded that single storey houses can have acceptable seismic performance even in high seismicity areas, provided that the structure is adequately strengthened by reinforced concrete columns and beams. Improvement of the characteristics of the structural material (earth) may be necessary to reduce damage.
\end{abstract}

(c) 2010 Elsevier Ltd. All rights reserved.

\section{Introduction}

For thousands of years, ever since cities have been built, earth has been used as a construction material. These constructions can be found all over the world with emphasis on Berber Africa, the Maghreb, the Near East, South and Central America and also Southern Europe. It is estimated that more than half the world population lives in earth constructions [1]. This is because it is a low-cost material available everywhere and it is recyclable, incombustible and provides good thermal insulation. In modern times earth has continued to be used in new constructions, especially in developing countries. However, nowadays a revival of this type of construction can be observed all over the world, including in developed countries, due to energy and environmental problems, coupled with a rising interest in architecture of this type of construction.

In these countries, however, earth construction is no longer a poor-quality low-price solution. A study made in Portugal [2] in which rammed earth walls were compared with solutions made with current hollow brick, adobe and compacted earth blocks walls showed that the rammed earth walls were the most expensive (about five times more per square meter than the low-quality current brick solution). However, when these rammed earth walls were included in a standard single-family cottage and compared with the equivalent global solutions with the other wall materials, the overall extra cost was reduced to only $15 \%$. This proves that

\footnotetext{
* Corresponding author. Tel.: +351218419709.

E-mail address: jb@civil.ist.utl.pt (J. de Brito).
}

rammed earth is an economically feasible solution providing the enticing advantages of better aesthetics, comfort and authenticity.

In Portugal, earth construction is also part of the built heritage. Even though no reliable sources can be cited concerning the initial date of the use of earth as a construction material, it is admitted that it goes as far back as the beginning of the pre-historical period.

However, earth construction suffers physical degradation with the passage of time, due especially to water, and its weak mechanical properties are an additional drawback. Most of these problems can be overcome by means of suitable improvements to material properties and constructive and strengthening solutions. The problem that may most severely restrict this type of construction is its poor strength, as the recent earthquake of 26 December 2003 in Bam, Iran, clearly showed. The fortress and most of the town's buildings, which were earth constructions, collapsed during the 6.6 magnitude earthquake. Fig. 1 shows the town before and after the earthquake.

Some studies have been performed using physical models in regions more prone to natural disasters, namely earthquakes. They aim at increasing the strength of these constructions and led to codes and regulations, namely the 1998 New Zealand Code [3], the 2006 New Mexico Code [4] and the 2002 Australian Standard [5], which all contemplate seismic structural strengthening. The main focus of these design codes is new buildings even though many of the principles can be applied to seismic retrofitting of existing structures.

There are also a few documents that deal with the basic concepts of structural design for earth construction, as well as the principles and considerations to be taken into account in relation to conservation because of the seismic vulnerability of these constructions. Two such publications are "Planning and 


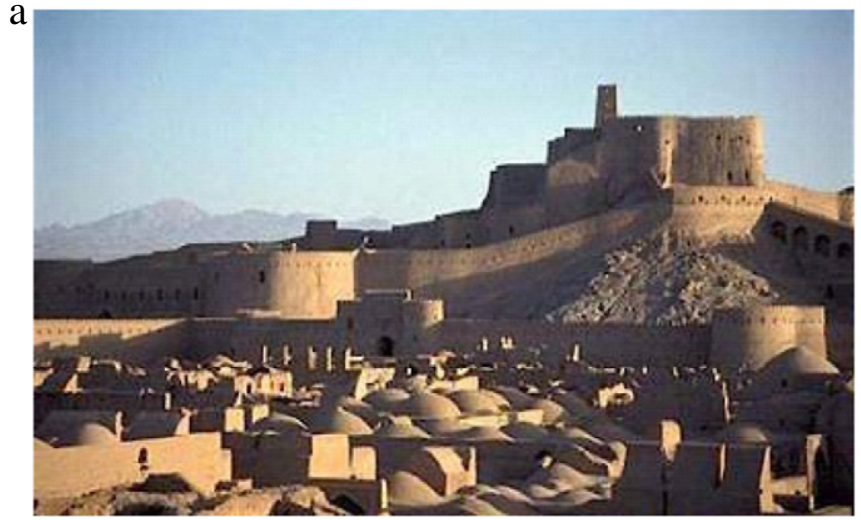

b

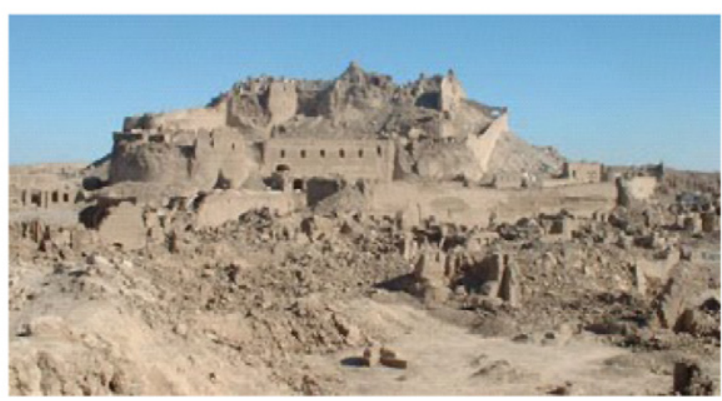

Fig. 1. The town of Bam in Iran: (a) before the December 2003 Earthquake and (b) after the December 2003 earthquake.

Engineering Guidelines for the Seismic Stabilization of Historic Adobe Structures" (2002) and "Seismic Stabilization of Historic Adobe Structures-Final Report of the Getty Seismic Adobe Project" (2002), both from the Getty Conservation Institute.

Even though there is a strong seismic activity in the south of the continent, European countries have not prepared earth constructions codes dealing with this issue. However, researchers are developing studies in order to improve the performance and strength of these constructions.

In order to study the possible use of earth as the main material in new construction in seismic zones, such as the south of Portugal, which is now witnessing a mild revival of rammed earth construction, a parametric study on a house of typical dimensions and adequate design was undertaken [6]. Five different typical structural strengthening solutions have been evaluated in order to identify those with the better seismic performance.

Some research is being carried out in this area but it scarcely deals with structural analysis. Very few studies have been made using numerical models of earth construction by means of finite elements, (e.g. [7,8], where conventional spectral analyses were performed using linear models). However some other researchers have presented experimental results based on real-scale models, developed from numerical models. For instance, Maniatidis and Walker [9] published a work on the structural capacity of earth columns subjected to compression with centred and eccentric loads. In order to study the strengthening of earth constructions, it is necessary to characterize the raw material, as Hall and Djerbib [10] did. The maximization of the mechanical strength of this type of construction may also be tackled by adding other materials as suggested by Jayasinghe and Kamaladasa [11]. Other researchers, such as Morel et al. [12], have analyzed the influence of the geometry of earth blocks in order to maximize their compression strength. Still other researchers, such as Jayasinghe and Mallawaarachchi [13], carried out tests in compressed stabilized earth bricks and blocks and stabilized rammed earth, in order to determine their flexural strength. In most research projects and experimental studies, real-scale models have been built in order to provide useful guidelines for suitable practices in this type of construction.

\section{Parametric study: overall description of the structures}

The aim of the parametric study is to analyse the potential seismic performance of typical Mediterranean rammed earth construction, one storey high with thick walls and small spans. For this purpose, a set of five structures with the same geometry and earth properties are analysed. The first one has no strengthening, while the other ones comprise different reinforcing solutions.

\subsection{Geometry}

Since the aim of this work is to study new construction, notwithstanding the fact that some of the strengthening solutions can also be used to rehabilitate existing constructions even though conservation issues may be raised if they are historic, there are no limitations on the choice of geometry. Therefore, this was based on the following recommendations aimed at providing lateral strength, which nonetheless are compatible with the dimensions and architecture of existing traditional earth constructions in Portugal:

- By Coburn et al. [14]: (i) regular, compact plan, (ii) one floor only, (iii) light roof, not made of earth, (iv) regular distribution of interior walls, (v) walls with neither long spans nor transverse support, and (vi) consistent foundations in competent soil.

- By Blondet et al. [15]: (i) height of the wall less than eight times its thickness, (ii) distance between parallel walls less than 10 times the thickness of the perpendicular walls, with a maximum of $7 \mathrm{~m}$, (iii) width of doors and windows less than $1.2 \mathrm{~m}$ and $1 / 3$ of unsupported wall length.

- By Peña and Lourenço [16]: (i) foundation depth between once and twice the wall thickness, and (ii) foundation extending at least $0.30 \mathrm{~m}$ above ground floor level to avoid erosion of earth by ground water.

All structures comprise one floor $2.8 \mathrm{~m}$ high. Fig. 2 shows the plan of all structures and a vertical cut of the foundations.

\subsection{Material properties}

The determination and calibration of the materials properties are not the main purpose of this research. Some of the properties used can vary by up to one order of magnitude depending on the source of the material and the reference consulted. Therefore, the material mechanical properties used in the analysis aim only at being plausible average values of the type of earth construction built in Portugal and the authors point to the fact that this subject must be further developed in future studies in order to evaluate the sensitivity of the conclusions reached here to the possible scatter of mechanical properties. However, the main conclusions are not expected to change from a qualitative but only a quantitative point of view. Young's modulus of rammed earth is taken as being $E=200 \mathrm{MPa}$ (NZ4297, 1998) and Poisson's ratio as 0.35 [17, 18]. The unit weight was assumed to be $19 \mathrm{kN} / \mathrm{m}^{3}$ [18]. According to the New Zealand Code [3], the maximum compressive stress can be taken as being $\sigma_{c}=E / 300$, yielding $\sigma_{c}=0.67 \mathrm{MPa}$. Varum et al. [19] suggest that the maximum tensile stress can be taken as $20 \%$ of the maximum compressive stress, yielding $\sigma_{t}=$ $0.67 / 5=0.13 \mathrm{MPa}$, a value that will be adopted in the analysis. New Zealand Standard NZ4297 [3] indicates that shear stresses below $\tau=0.08 \mathrm{MPa}$ can be considered acceptable, a conclusion drawn from experimental tests. However, this value could be seen as very conservative, which is why NZ 4929 also accepts higher values for shear stresses if tests are performed to evaluate the rammed earth's compressive strength, $\sigma_{c}$. In these cases, the shear 
a

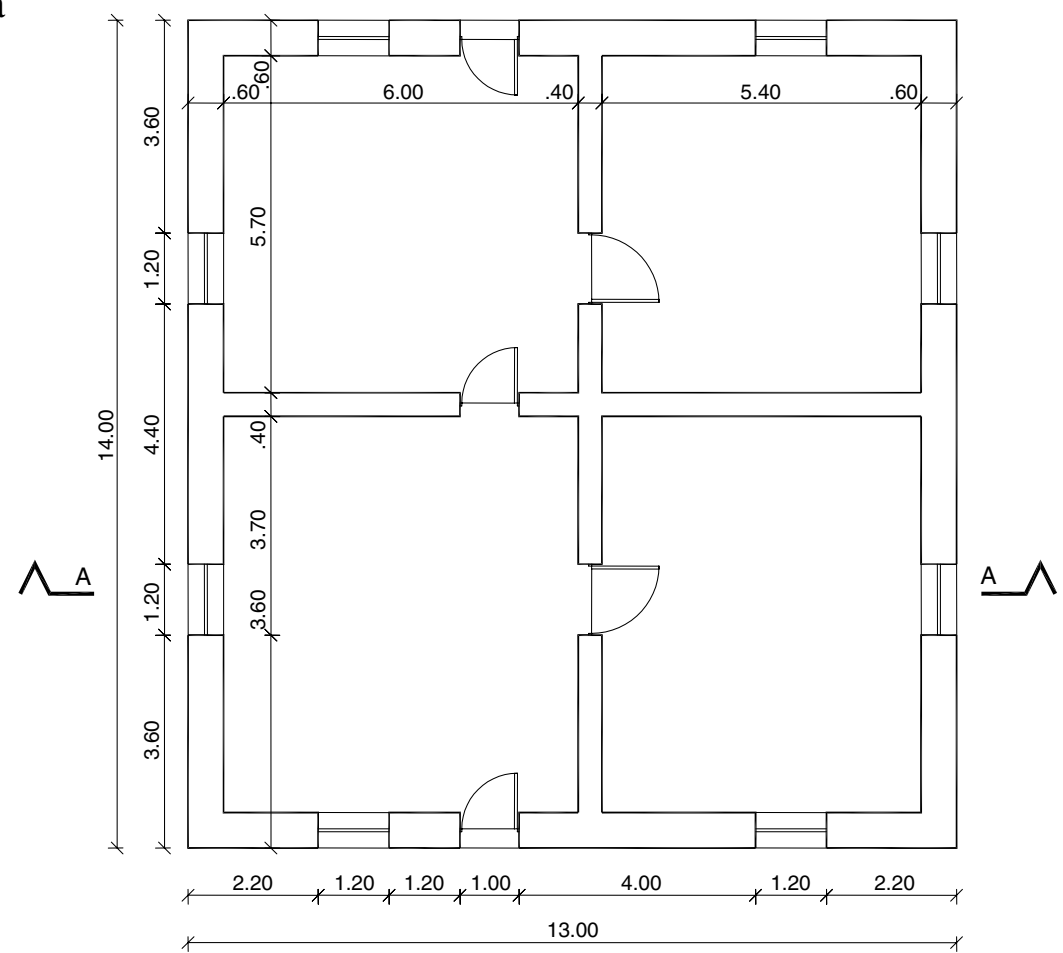

b

All units in meters $(\mathrm{m})$

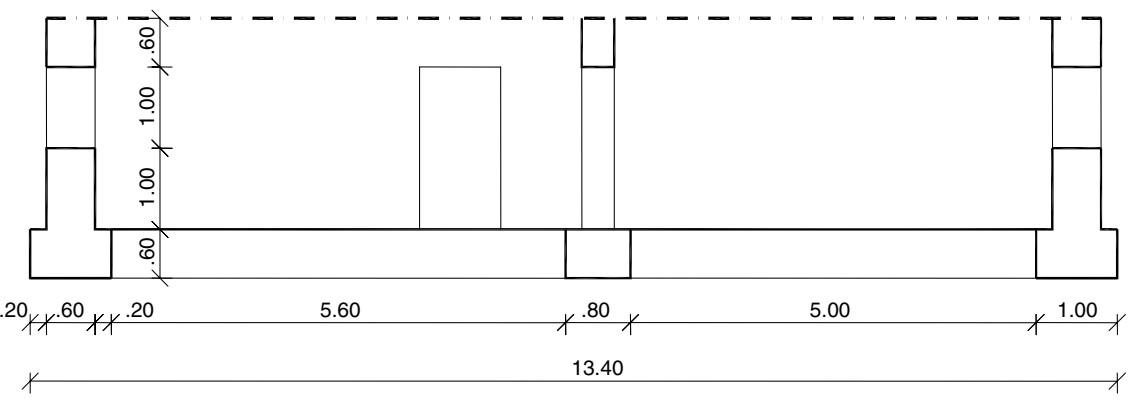

All units in meters $(\mathrm{m})$

Fig. 2. Plan of the structures and vertical section of the foundations.

stress can be the higher value given by the two equations below:

$\tau=0.07 \times \sigma_{C}$.

Or

$\tau=70+5 \times h(\mathrm{kPa})$

where $h$ represents the height of the wall in meters.

According to these equations, the acceptable shear stress, assuming that $\sigma_{c}=0.67 \mathrm{MPa}$ and $h=2.6 \mathrm{~m}$, is calculated to be:

$$
\begin{aligned}
\tau & =0.07 \times 0.670=0.047 \mathrm{MPa} \\
\tau & =(70+5 \times 2.6) / 1000=0.083 \mathrm{MPa},
\end{aligned}
$$

which is only slightly above the recommended value of $\tau=$ $0.08 \mathrm{MPa}$. Other authors, like Jaquin and Augarde [7], propose formulas calibrated from experimental results that yield acceptable shear stress values between 0.07 and $0.8 \mathrm{MPa}$. In this work, the value of $\tau=0.08 \mathrm{MPa}$ is taken as the acceptable upper limit for the shear stresses.

The strengthening materials used are stone (in Portugal limestone, granite, schist or basalt), timber (in Portugal maritime pine, oak or chestnut) and reinforced concrete (RC). The properties assumed for these materials, including their unit weight, are shown in Table 1.
Table 1

Material properties.

\begin{tabular}{llll}
\hline & Stone & Timber & Concrete $\mathrm{C} 20 / 25$ \\
\hline$E(\mathrm{MPa})$ & $10000[23]$ & $10000[24,25]$ & 29000 \\
Poisson's ratio & 0.2 & 0.2 & 0.2 \\
Unit-weight $\left(\mathrm{kN} / \mathrm{m}^{3}\right)$ & 22 & 6 & 25 \\
\hline
\end{tabular}

\subsection{Specific description of the different studied structures}

The first structure is an unreinforced building made only of rammed earth, apart from the foundations (in stone), the roof structure (in timber) and a $0.20 \mathrm{~m}$ thick timber beam on top of all openings, as shown in Fig. 3.

Structure 2 is reinforced by means of visible stone elements around the borders of all door and window openings. The thickness of the stone elements is the same as the one of the walls $(0.60 \mathrm{~m})$ and the other cross-section dimension is $0.20 \mathrm{~m}$. This strengthens some of the locations where the highest stresses occur. All corners and intersections of walls are also reinforced with $0.40 \mathrm{~m}$ wide stone elements, as shown in Fig. 4. This improves the behaviour of orthogonal walls under horizontal loads.

Structure 3 can be obtained by adding steel cables ( $\phi 16$, S400) at the top of the walls connecting the perpendicular walls, a type 


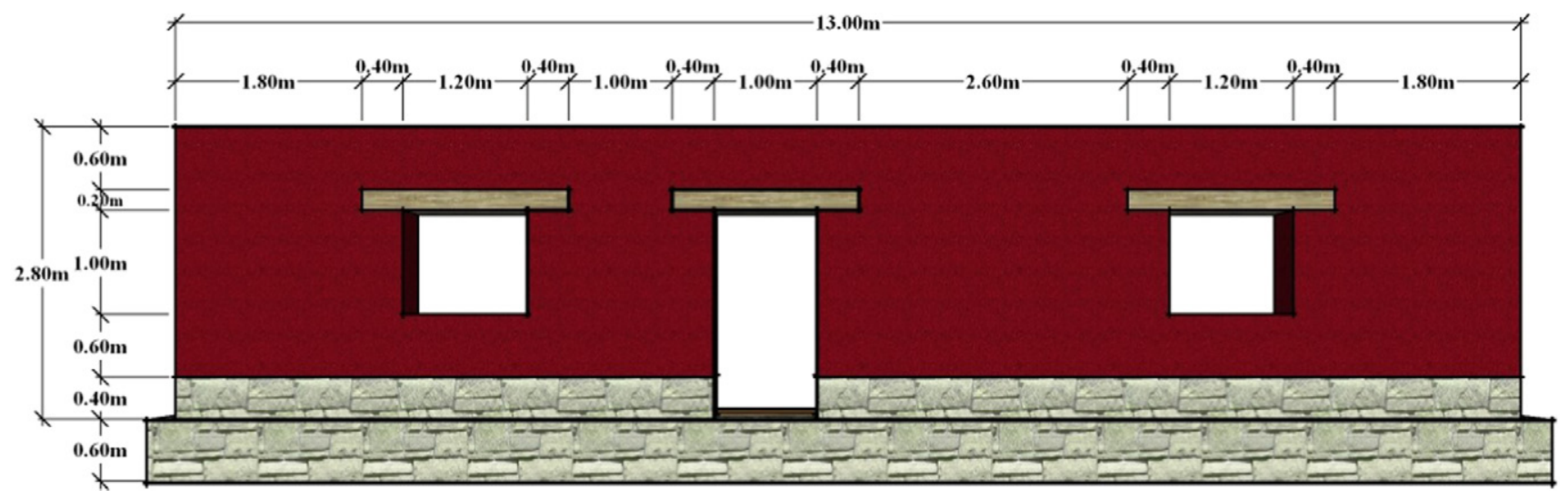

Fig. 3. Side view of structure 1.

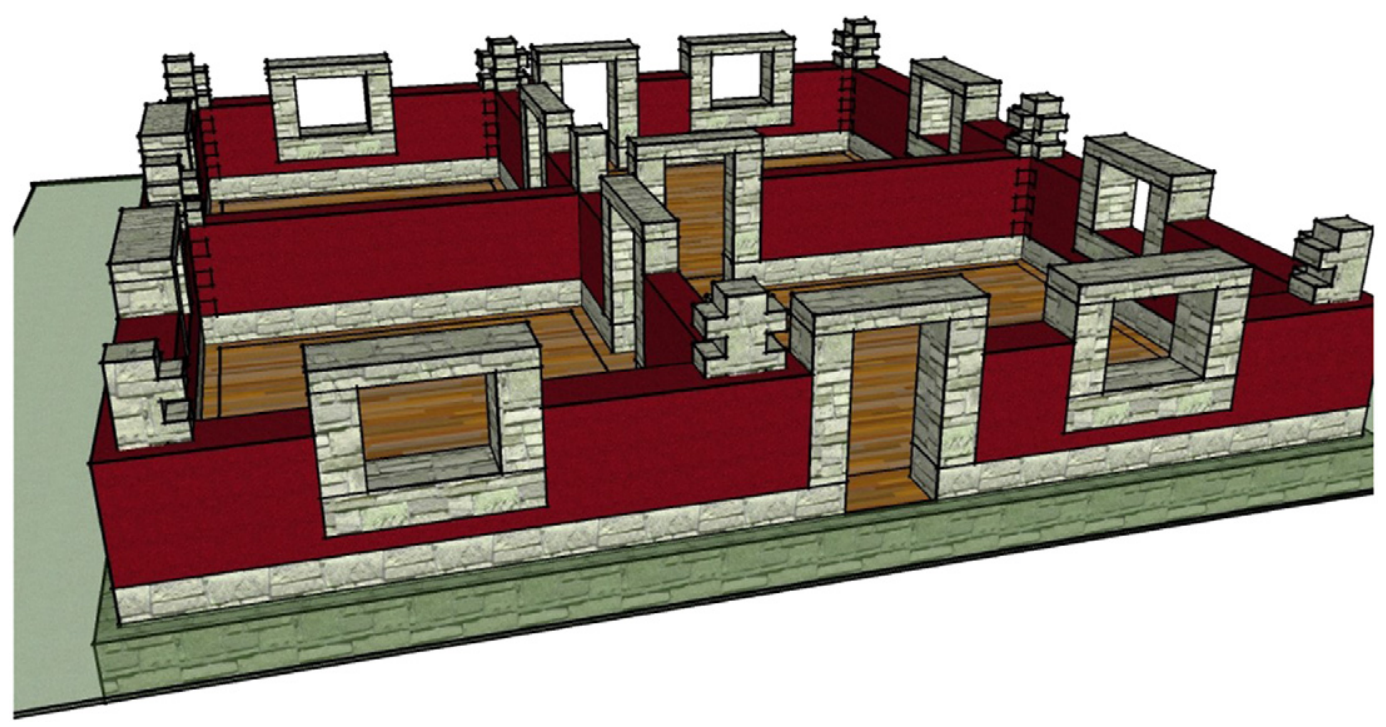

Fig. 4. Perspective of the stone reinforcement at the structure 2 .

of strengthening widely used in masonry construction in Portugal and elsewhere. Fig. 5 shows the anchorages of these cables in real constructions and Fig. 6 defines the location of the cables.

Structure 4 can be obtained from structure 2 with an RC beam along the top of all walls. Depending on its thickness, it may be visible or completely hidden within the earth walls, as it is here, since the beam's cross-section is $0.20 \times 0.20 \mathrm{~m}^{2}$. It is assumed that the beams are properly connected to the earth walls and stone columns at the corners and intersections of orthogonal walls. This can be achieved by means of bolts or indentations, for example. Therefore despite the differences of stiffness between different materials, it is assumed that there is no slip at the interfaces. This is enforced in the model by establishing compatibility of displacements at the interfaces.

In structure 5, the columns and foundations of structure 4 are replaced by RC elements. The RC columns are $0.20 \times 0.20 \mathrm{~m}^{2}$, and are embedded in the earth panels and therefore are not visible. Even though in practical terms the structure can be considered as a 3D reinforced concrete frame filled with earth panels with partition and resisting functions, the architectural concept is one of an earth construction (namely in terms of the thickness of the walls due to the procedures needed to produce rammed earth) that is reinforced in the inside to resist seismic actions (and namely to prevent the earth walls from collapsing by being confined at the tops). Fig. 7 shows a house of this type, but with purposely larger, visible beams and columns. Even though it is known that for confined masonry, properties of the confined panels (here the earth panels) are enhanced as regards shear resistance and deformation capacity, this effect was not taken into account because a conservation stance has been adopted throughout the study.

In short, the walls in structure 1 are made of rammed earth only with stone foundations; structure 2 is the same as 1 with stone elements around the openings; structure 3 is the same as 2 with steel cables; structure 4 is the same as 2 with a RC beam at the top; structure 5 is the same as 4 with RC foundations and columns.

\subsection{Actions}

All five structures were analysed for the same actions, the weight of the structure $(G)$ and the seismic action $(E)$. The weight of the walls was modelled directly at the level of each element, inducing mainly vertical compressive stresses in all walls.

The roof is assumed to be a timber framework covered with tiles and having a distributed weight of $0.5 \mathrm{kN} / \mathrm{m}^{2}$. It is also assumed that the roof does not transfer horizontal loads to the walls due to its own weight, as recommended in this type of construction. It must therefore be horizontally braced if it comprises nonhorizontal beams, to distribute the associated mass and weight along the nodes on the top of the structure in the zones where it would be supported on the structure. Even though some axial restraint may exist in one direction, this type of roof structure does not provide diaphragmatic action. Therefore, this was not 

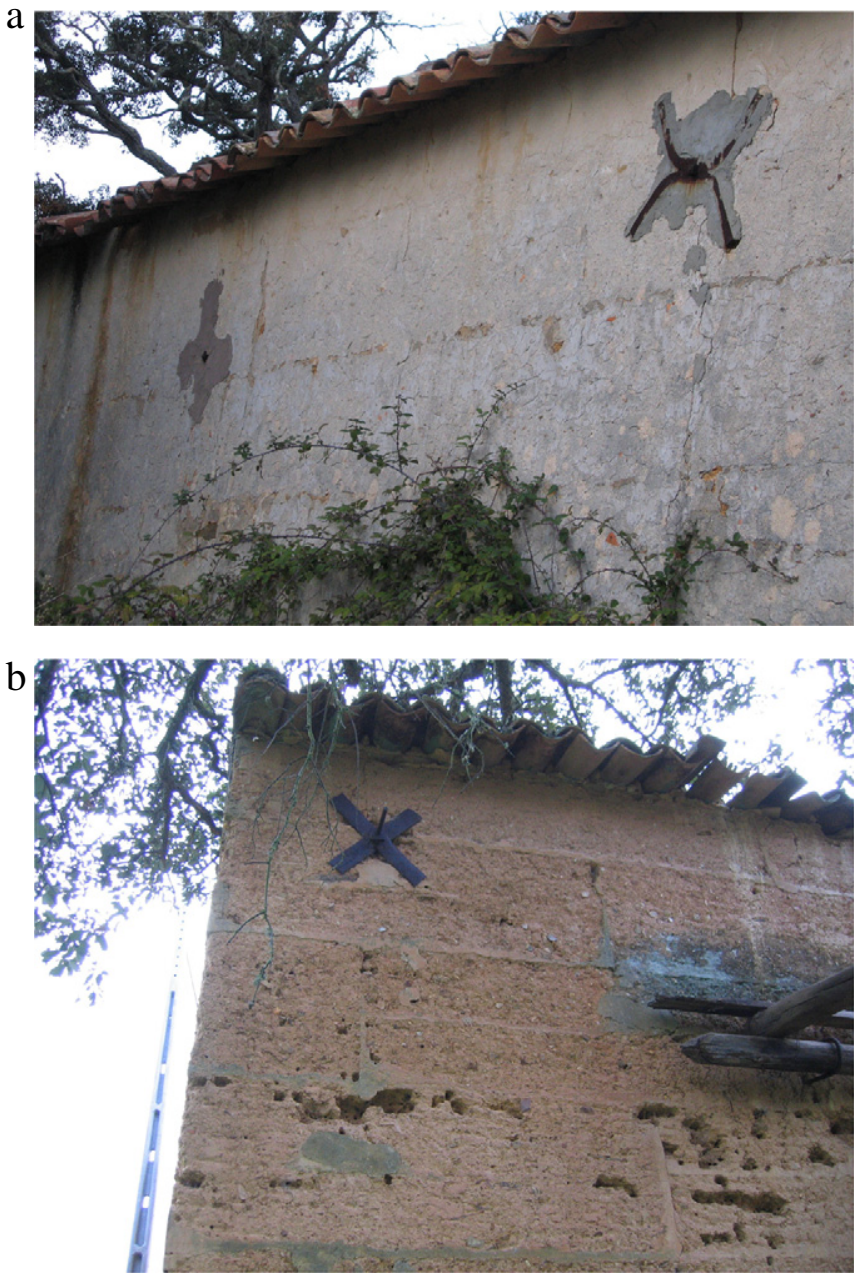

Fig. 5. Anchorage of steel cables in earth structure in S. Luís, Portugal.

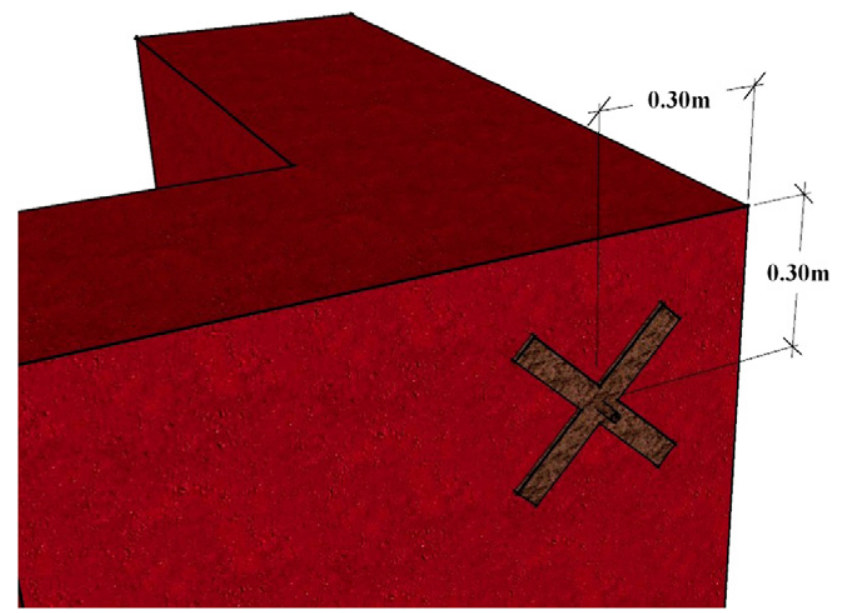

Fig. 6. Detail of the location of the cables.

explicitly considered in the models in which the roof masses were modelled as additional masses on the nodes at the top of the exterior walls. However in models 4 and 5, the top RC beams restrain horizontal deformations in the horizontal plane at the top of the walls, producing a partial diaphragmatic effect.

The elastic horizontal acceleration response spectrum for $5 \%$ damping prescribed in the Portuguese code of actions [20] was used in this work and is shown in Fig. 8. It is associated with

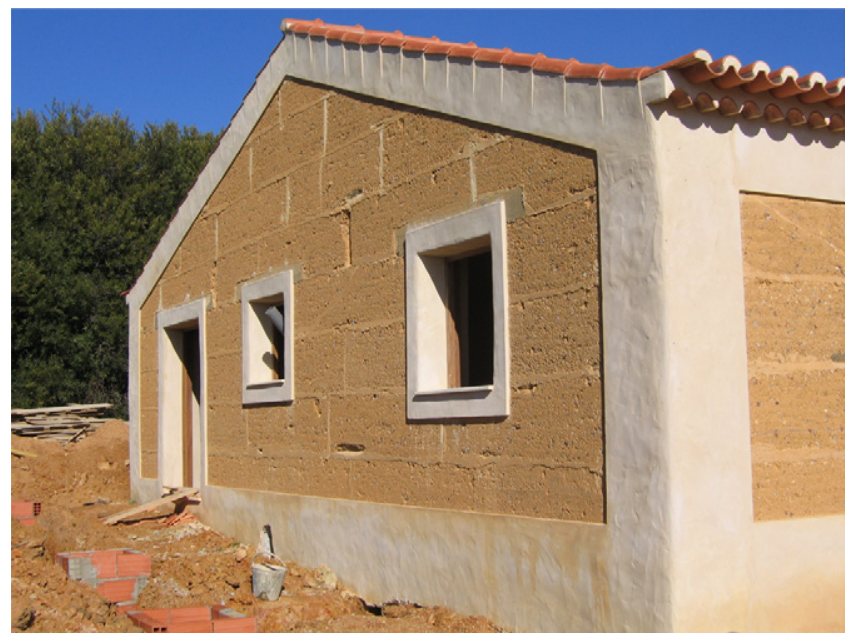

Fig. 7. Earth house with RC beams and columns in S. Luís, Portugal.

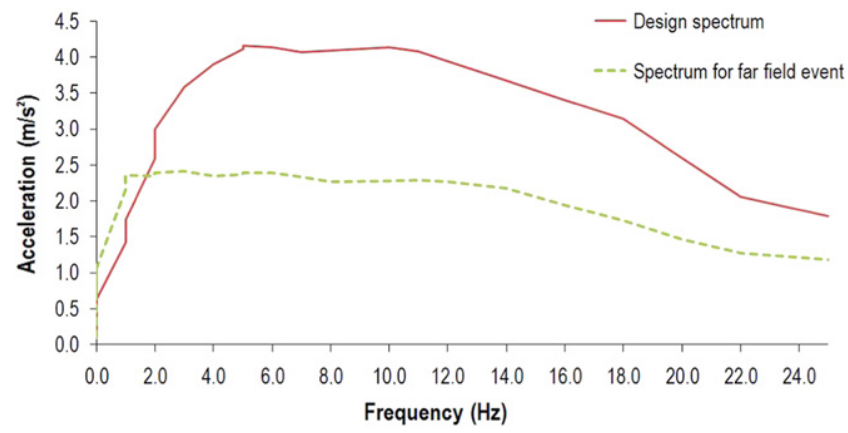

Fig. 8. Response spectrum.

the highest seismicity zone in Portugal (Zone A), which includes Lisbon and the south, where earth construction is more frequent, and with a soil of average stiffness, corresponding to $N_{\mathrm{SPT}}=40$. The response spectrum for vertical accelerations was obtained by multiplying the spectrum for horizontal accelerations by $2 / 3$ (Fig. 8), as prescribed in RSA. The two horizontal and the vertical components of the seismic action were considered simultaneously and their effects combined by means of the SRSS (square root of sum of squares) rule.

The combinations of actions considered were

Vertical loads: $1.5 \mathrm{G}$.

Seismic combinations: $G \pm 1.5 E$.

The peak ground acceleration corresponding to $1.5 \mathrm{E}$ is $0.265 \mathrm{~g}$.

(G-Gravity loads; E-earthquake action; $g$-acceleration of gravity).

\subsection{Structural modelling}

The stresses in the structure were analyzed by means of a threedimensional finite element model and linear dynamic analysis by response spectra using SAP2000 [21] software. The limitations of this type of analysis and its influence on the conclusions are discussed later.

Since the walls are quite thick, and one of the expected mechanisms of damage for this type of structure is the out-of-plane movement of the earth panels, it is relevant to simulate the out-ofplane behaviour. For this reason, the structure was modelled using three-dimensional solid elements with eight nodes and 3 degrees of freedom per node and dimensions of $0.20 \times 0.20 \times 0.20 \mathrm{~m}^{3}$. The only exceptions were the steel cables, which were modelled as linear pinned bars. 
Table 2

Dynamic characteristics of structure 1 .

\begin{tabular}{|c|c|c|c|c|c|c|c|c|}
\hline \multirow[t]{2}{*}{ Mode } & \multirow[t]{2}{*}{ Period (s) } & \multirow[t]{2}{*}{ Frequency $(\mathrm{Hz})$} & \multicolumn{3}{|c|}{ Mass participation } & \multicolumn{3}{|c|}{ Accumulated mass participation } \\
\hline & & & $U_{x}$ & $U_{y}$ & $U_{z}$ & $U_{x}$ & $U_{y}$ & $U_{z}$ \\
\hline 1 & 0.188 & 5.31 & 0.07 & 0.23 & $4.3 \mathrm{E}-7$ & 0.07 & 0.23 & $4.3 \mathrm{E}-7$ \\
\hline 2 & 0.173 & 5.77 & 0.85 & 1.16 & $3.5 \mathrm{E}-5$ & 0.92 & 1.39 & $3.5 \mathrm{E}-5$ \\
\hline 3 & 0.165 & 6.06 & 1.44 & 1.09 & $1.7 \mathrm{E}-4$ & 2.36 & 2.48 & $2.1 \mathrm{E}-4$ \\
\hline 4 & 0.164 & 6.11 & 0.63 & 3.58 & $4.3 \mathrm{E}-6$ & 2.99 & 6.06 & $2.1 \mathrm{E}-4$ \\
\hline 5 & 0.156 & 6.41 & 7.80 & 0.51 & $9.5 \mathrm{E}-4$ & 10.79 & 6.57 & $1.2 \mathrm{E}-3$ \\
\hline 19 & 0.077 & 13.07 & 0.18 & 0.23 & $1.8 \mathrm{E}-3$ & 35.47 & 34.06 & $7.0 \mathrm{E}-2$ \\
\hline 20 & 0.073 & 13.79 & 0.12 & 0.96 & $2.0 \mathrm{E}-6$ & 35.60 & 35.02 & $7.0 \mathrm{E}-2$ \\
\hline 199 & 0.017 & 59.64 & 0.01 & 0.00 & $6.5 \mathrm{E}-5$ & 60.53 & 60.35 & 53.30 \\
\hline 200 & 0.017 & 59.74 & 0.00 & 0.01 & $1.1 \mathrm{E}-3$ & 60.53 & 60.37 & 53.30 \\
\hline
\end{tabular}

\section{Results}

The results for the unreinforced structure (1) are given in more detail. For all other structures only the most relevant differences are highlighted, for the sake of compactness.

\subsection{Unreinforced structure}

The main dynamic characteristics of structure 1 are summarised in Table 2.

The main features shown by the above results are as follows:

- The frequency of the first mode $f_{1}=5.31 \mathrm{~Hz}$ indicates that the earth structures are more sensitive to earthquakes with a high frequency content; the Portuguese code also prescribes a lowfrequency seismic action, corresponding to a far-field event of greater magnitude than the seismic action used for the analysis; the far-field seismic action was not considered, because above $2 \mathrm{~Hz}$ spectral acceleration is always lower than for the seismic action used in the analysis, associated with a near-field event of moderate magnitude;

- With 20 modes the mass participation is around 35\% in both horizontal directions; since this value is low, in order to study the influence of the number of modes in the reliability of the results, the dynamic analyses were also performed considering 200 modes; in this case the accumulated mass participation is slightly above $60 \%$ in the horizontal directions; this increase is due to the existence of many modes associated with local deformations of parts of the structure, since there is no rigid floor; the difference to $100 \%$ is attributed not only to the fact that not all local modes were captured, but essentially because a significant part of the mass that is in or near the foundations; since these nodes have little or no displacements, the associated masses only contribute to very high frequency modes that have almost no influence on the seismic behaviour; this is illustrated by the fact that if the masses of the foundation (up to the bottom of the earth walls) were removed from the model, the mass participation would increase to $89 \%$ in both horizontal directions, which is an acceptably high value;

- The frequency of the 20th mode, $f_{20}=13.79 \mathrm{~Hz}$, is on the right-hand side descending branch of the design acceleration response spectrum, shown in Fig. 8; this indicates that higher modes, associated with higher frequencies, will be associated with lower values of spectral accelerations than the first modes, thus having little influence on the overall structural response;

- The mass participation of the first modes is very low, at least compared with the usual values in buildings with rigid floors; the first three modes are associated with local out-of-plane deformations of the inner walls, with the largest displacement on top of the walls; the fourth mode is the first with relevant displacements of the exterior walls and is also a local mode; this should be expected, as the inner walls are not as thick as the exterior walls, and therefore the inner walls are more flexible and less resistant to local deformations; Fig. 9 illustrates the shape of the first and fourth modes.
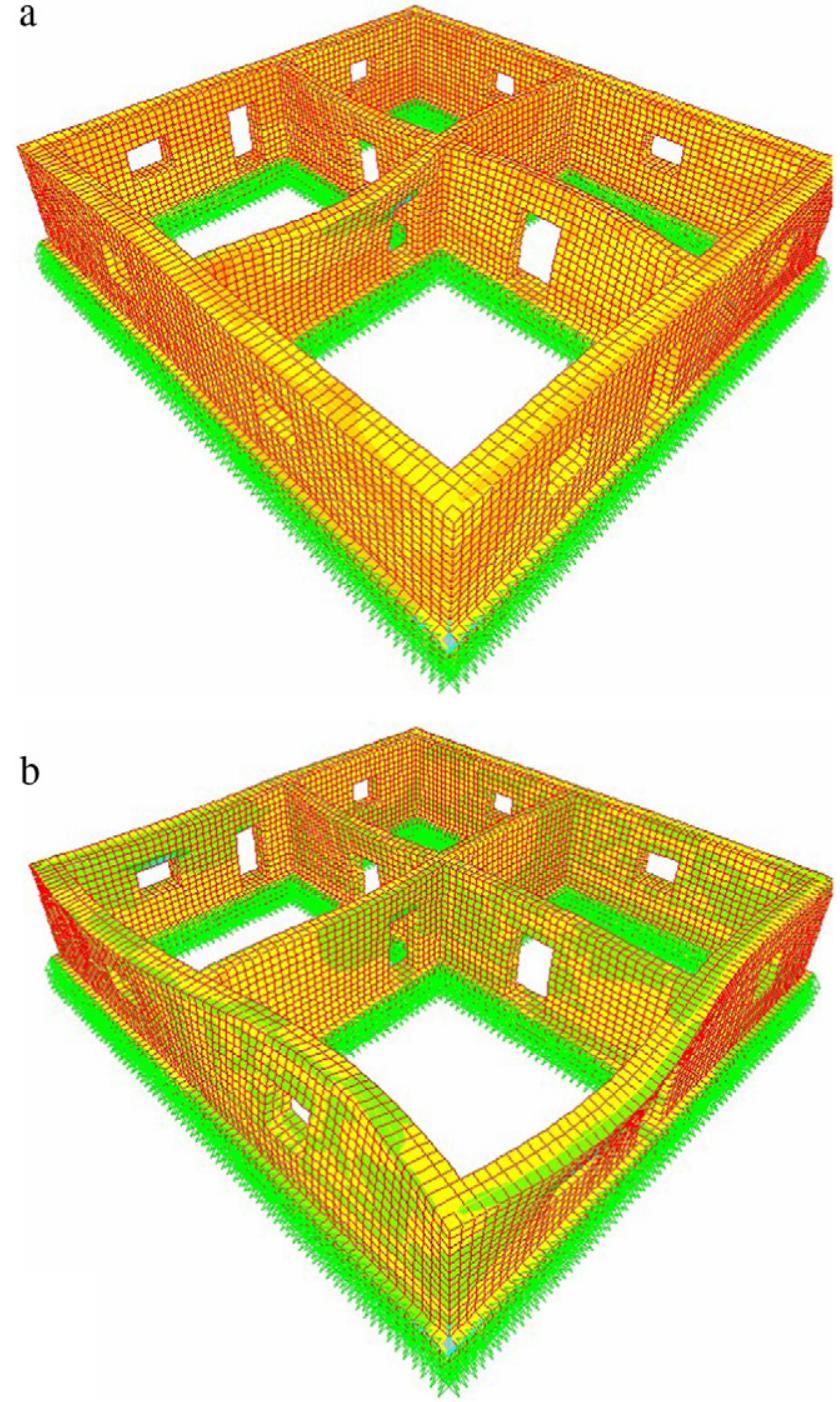

Fig. 9. Shape of the first mode (left) and fourth mode (right) for the nonstrengthened structure.

Table 3 shows the maximum displacements in the points identified in Fig. 10 (the ones with the highest stresses and displacements) for the seismic combinations considering respectively 20 and 200 modes in the dynamic analysis of structure 1 . The fact that the displacements are the same in both analyses shows that the modes above the 20th mode have practically no influence on the displacements the structure must withstand. The comparison of the results of the two dynamic analyses in terms of stresses shows exactly the same trend, as expected. This result was also observed for all other structures. Given the large number of degrees of 


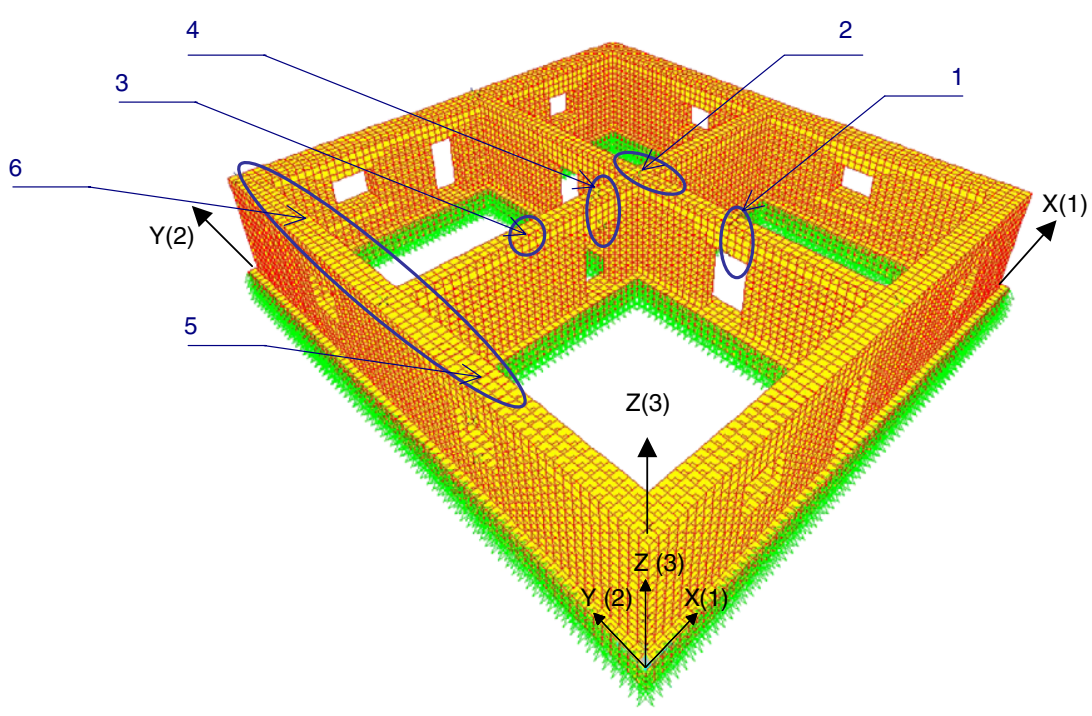

Fig. 10. Identification of nodes.

Table 3

Greatest displacements for the seismic combination (dynamic analysis with 20 modes of vibration) of structure 1 .

\begin{tabular}{lllllll}
\hline Node no. & 1 & 2 & 3 & 4 & 5 & 6 \\
\hline Longitudinal direction $(\mathrm{mm})$ & 0.6 & $0.8(0.8)$ & 0.79 & $0.5(0.5)$ & $0.6(0.6)$ & $0.6(0.6)$ \\
Transverse direction & 9.1 & $0.8(0.8)$ & 9.21 & $4.3(4.3)$ & $4.3(4.3)$ & $3.1(3.1)$ \\
$(\mathrm{mm})$ & & & & & & \\
\hline
\end{tabular}

The values in brackets were obtained considering 200 modes of vibration in the dynamic analysis.

freedom of the structure, 67554 , the analysis with 200 modes is considerably more time-consuming than the analysis with 20 modes; therefore, and since the modes 21-200 do not influence the relevant results, all other dynamic analysis (structures 2-5) were performed without considering these modes.

Regarding the above results for the displacements, the main point to be noted is that the maximum displacement of $9.2 \mathrm{~mm}$ is $0.3 \%$ of the height of the walls, which is an acceptable value (given the limit of $0.5 \%$ in EC8 for inter-storey drift for a service seismic action - half the design seismic action considered in this study for damage control in fragile non-structural elements).

Regarding the stresses, it is of relevance to highlight the largest tensile stresses for the seismic combination, shown in Fig. 11. The evaluation of maximum shear stresses is also of relevance. Note that in the framework of dynamic modal analysis it is not possible to obtain the principal stresses since the principal directions at each point may be different from mode to mode. Therefore, it is indispensable to verify shear stresses as well, to which large tensile stresses in a different direction may correspond.

Fig. 11 shows that the maximum tensile stresses occur at the top of the intersection of the inner walls with the exterior walls $\left(\sigma_{11}=0.450 \mathrm{MPa}\right)$ and at the top of the intersection of the inner walls $\left(\sigma_{11}=0.254 \mathrm{MPa}\right)$; in both cases the stresses are in the direction of the largest dimension of the wall. These values were determined approximately considering the average of maximum stresses in areas (not single points) the size of one finite element $(20 \mathrm{~cm} \times 20 \mathrm{~cm} \times 20 \mathrm{~cm}$ ), but are accurate enough to support the conclusions that will be derived. In the orthogonal direction the behaviour is similar, but the maximum stresses are slightly lower, $\sigma_{22}=0.430 \mathrm{MPa}$ and $\sigma_{22}=0.242 \mathrm{MPa}$, respectively. In either case the maximum allowable tensile stress is largely exceeded in several locations in the structure. Tensile stresses above the acceptable limit also occur near the corners of walls and windows ( $\sigma_{11}=0.215 \mathrm{MPa}$ ), and at the base of the walls near the
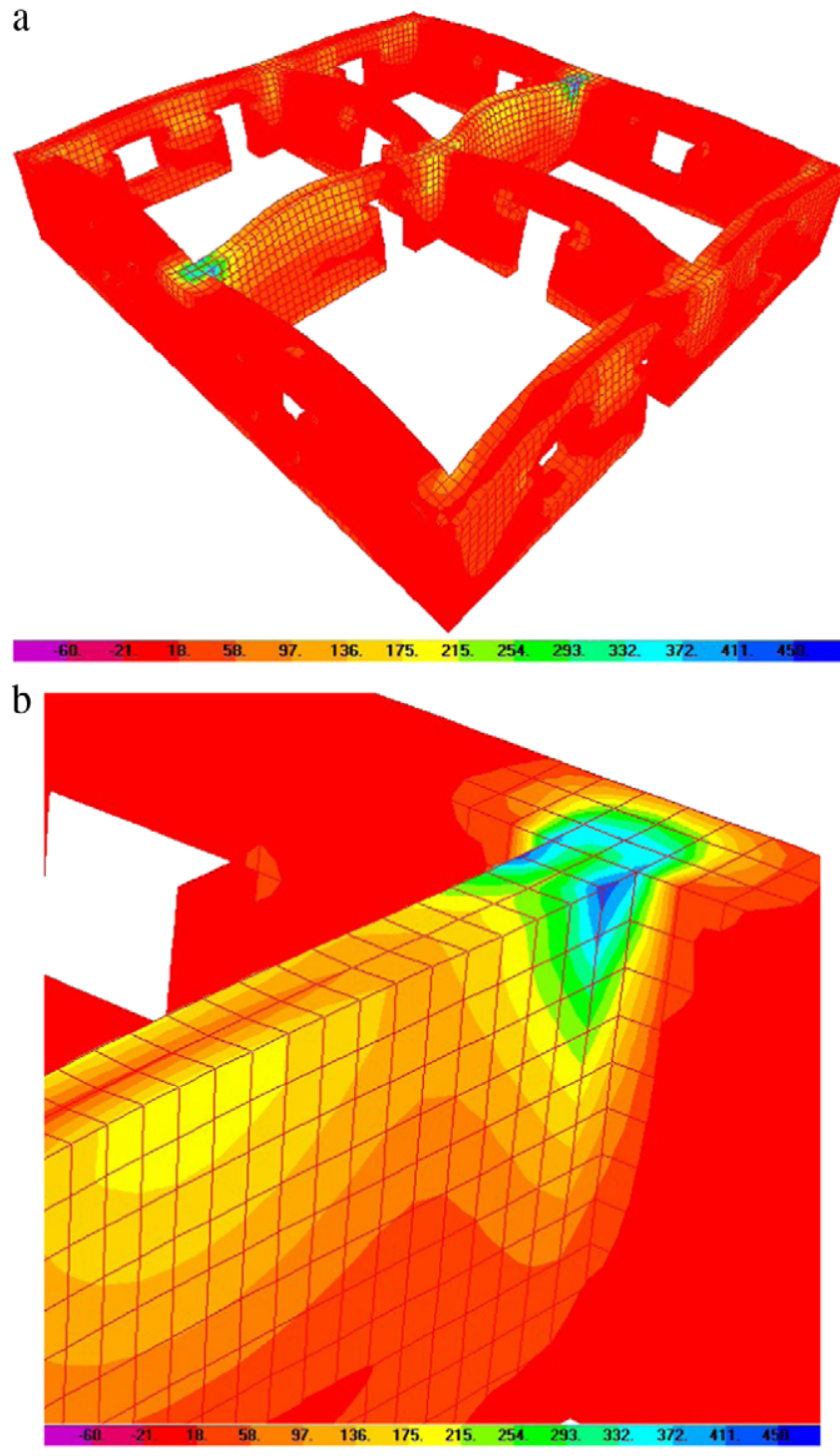

Fig. 11. Greatest tensile stresses for the seismic combination.

openings in the zone of the extension of the foundation (stone). The maximum compressive stress is not exceeded at any location. 
Table 4

Maximum tensile and shear stresses in earth elements.

\begin{tabular}{|c|c|c|c|c|c|}
\hline & $\begin{array}{l}\text { Stresses on top of the } \\
\text { intersection of inner walls } \\
(\mathrm{MPa}) \sigma_{11}\end{array}$ & $\begin{array}{l}\text { Stresses on top of the } \\
\text { intersection of inner and } \\
\text { exterior walls }(\mathrm{MPa}) \sigma_{11}\end{array}$ & $\begin{array}{l}\text { Stresses above and in the } \\
\text { corners of windows and } \\
\text { doors (MPa) }\end{array}$ & $\begin{array}{l}\text { Shear stresses near doors } \\
\text { and windows (MPa) } \tau_{13}\end{array}$ & $\begin{array}{l}\text { Shear stresses at the corners } \\
(\mathrm{MPa}) \tau_{12}\end{array}$ \\
\hline Structure 1 & 0.254 & 0.450 & $0.215-\sigma_{11}$ & 0.102 & 0.092 \\
\hline Structure 2 & 0.188 & 0.250 & $\begin{array}{l}0.147-\sigma_{22} \\
0.105-\sigma_{11}\end{array}$ & 0.130 & 0.030 \\
\hline Structure 3 & 0.188 & 0.250 & $\begin{array}{l}0.149-\sigma_{22} \\
0.105-\sigma_{11}\end{array}$ & 0.140 & 0.040 \\
\hline Structure 4 & 0.148 & 0.160 & $0.086-\sigma_{11}$ & 0.090 & 0.030 \\
\hline Structure 5 & 0.135 & 0.160 & $0.098-\sigma_{11}$ & 0.060 & 0.040 \\
\hline
\end{tabular}

The maximum shear stresses are $\tau_{13}=0.102 \mathrm{MPa}$ near doors and windows and $\tau_{12}=0.092 \mathrm{MPa}$ at the corners.

The above results are enough to show that under the design seismic action the structure would certainly suffer extensive damage, whose consequences are difficult to evaluate in the context of linear analysis, since the redistribution of stresses associated with exceeding the maximum stress in some locations and the possible spread of damage were not studied in this work.

\subsection{Strengthened structures}

The second and third structures exhibit similar dynamic characteristics, the main difference from the non-strengthened structure being increased stiffness and frequencies, due to the stiffer stone elements at wall intersections. The accumulated mass participation factors associated with the first 20 modes falls to $27 \%$ in both main directions. The cables included in the third model had little influence on the stiffness. Even though the shape of the first modes is similar to those for the unreinforced structure, the frequencies of the first modes $f_{1}=7.39 \mathrm{~Hz}$ and $f_{2}=7.94 \mathrm{~Hz}$ of both structures, clearly show an increase.

The introduction of the top beams in structure 4 led not only to an increase in stiffness and frequencies but also forced the structure to work more efficiently as a whole than in the previous cases. This is strongly reflected in the accumulated mass participation factors, which were $51 \%$ and $49 \%$ in each direction for the first 20 modes, and in the mode shapes. If the mass of the foundation were not considered these values would be $89 \%$ in both horizontal directions which is perfectly acceptable. Fig. 12 shows the first and third mode shapes, which show simultaneous out-ofplane movements of inner and outer walls, a degree of coupling not observed in structures $1-3$. The increased stiffness compared with the previous structures was obviously reflected in the frequencies, which for the first modes were $f_{1}=9.38 \mathrm{~Hz}$ and $f_{2}=9.66 \mathrm{~Hz}$. The dynamic behaviour of structure 5 is qualitatively similar to that of structure 4.

The maximum out-of-plane displacements for the seismic combination are smaller in the strengthened structures. Structures 2 and 3 exhibit maximum displacements of $5.20 \mathrm{~mm}$ and $5.49 \mathrm{~mm}$ respectively, which is a reduction to slightly more than half the displacements of the non-strengthened structure. This shows that the introduction of stiffer stone elements was effective at reducing out-of-plane displacements, but that the cables connecting opposite walls were not effective at reducing out-of-plane displacements of structures already strengthened with stone elements at the wall intersections. The introduction of the $\mathrm{RC}$ beams on top of the walls is even more effective at reducing out-of-plane displacements, as the structures strengthened with these elements exhibited maximum out-of-plane displacements of $2.96 \mathrm{~mm}$ and $2.39 \mathrm{~mm}$, respectively.

As far as the stress analysis is concerned the best indicators of damage and safety levels are the maximum tensile and shear stresses in the earth elements. Table 4 shows the stresses induced by the seismic combination in the strengthened structures and also in structure 1 to facilitate the comparison. The maximum
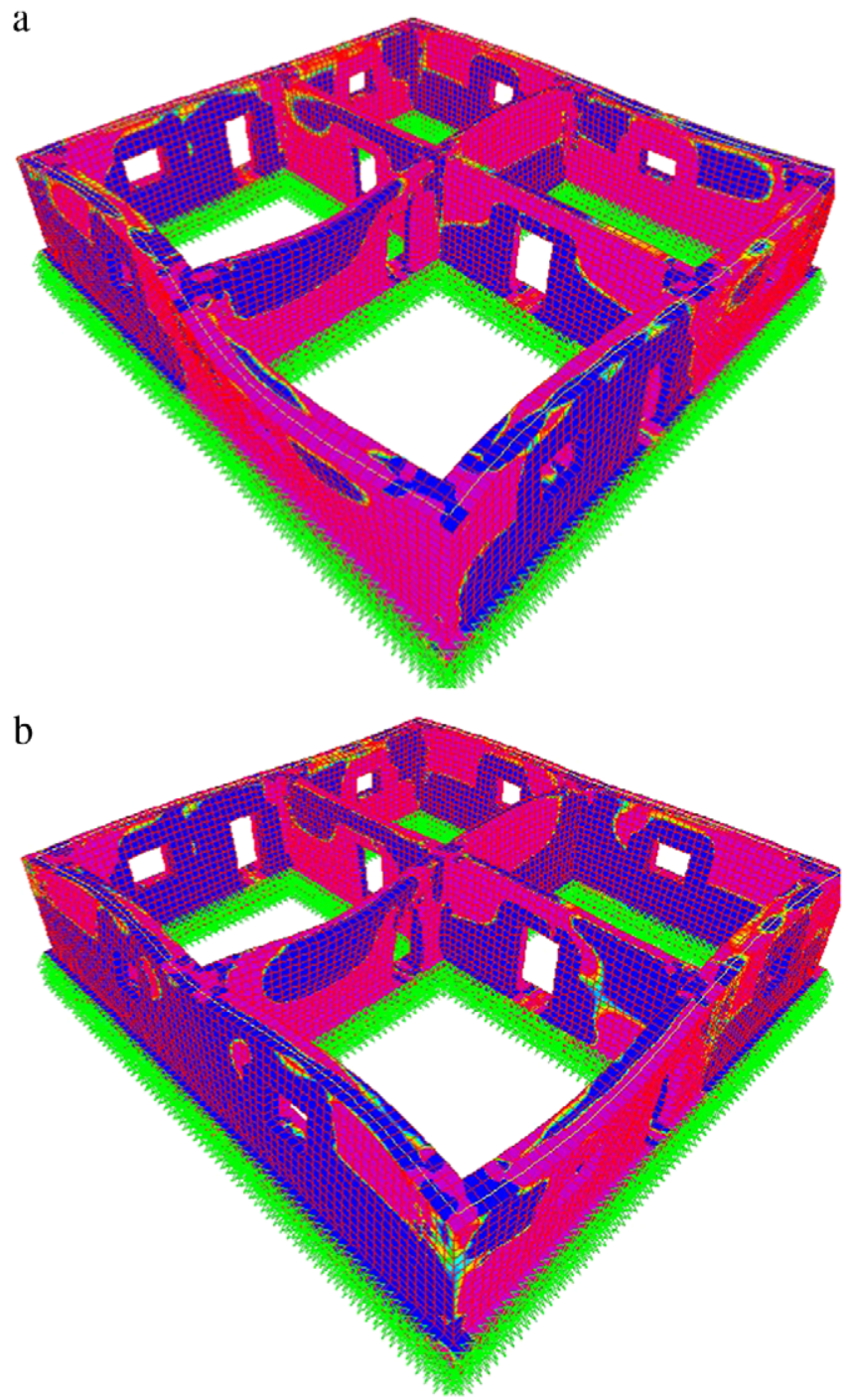

Fig. 12. Shape of the first mode (left) and third mode (right) for structure 4

compressive stresses in the structure are similar to the maximum tensile stresses.

The results show that the strengthening strategies adopted are very effective at reducing stresses in the earth elements, especially the solution based on RC beams and columns. Even though the maximum tensile stresses in these cases (structures 4 and 5) are still above the acceptable limit, indicating that the structure would suffer some damage under the design seismic action, the difference from the acceptable values is much smaller than for the nonstrengthened structure.

Also using spectra analyses and considering material linear behaviour, other authors, such as Blondet et al. [22] and Parreira [23], have also concluded that the use of a reinforced 
Table 5

Maximum tensile stress for different seismic zones.

\begin{tabular}{|c|c|c|c|c|c|}
\hline$\sigma(\mathrm{MPa})$ & Structure 1 & Structure 2 & Structure 3 & Structure 4 & Structure 5 \\
\hline Zone A & 0.450 & 0.250 & 0.250 & 0.160 & 0.160 \\
\hline Zone B & 0.300 & 0.175 & 0.175 & 0.115 & 0.120 \\
\hline Zone C & 0.200 & 0.125 & 0.125 & 0.080 & 0.080 \\
\hline Zone D & 0.120 & 0.085 & 0.080 & 0.050 & 0.050 \\
\hline
\end{tabular}

concrete or timber beam connecting the top of the earth walls is a very effective seismic strengthening strategy, as it makes the construction act as a whole under horizontal forces and restricts out-of-plane failure of the wall panels. A series of tests on earth dwellings under horizontal forces, performed by Zegarra et al. [24] according to strengthening strategies used in the reconstruction of Arequipa in Peru [25], also confirmed the efficacy of reinforced concrete beams connecting the top of the walls.

\subsection{Zones with lower seismicity}

The above results concern the design seismic action in the zone of highest seismicity in Portugal, the zones closer the epicentre of Lisbon's great earthquake of 1755 . The zones further north suffer less seismicity, as quantified by means of a seismicity coefficient, $\alpha$, that multiplies the seismic action in the zone of highest seismicity, zone $A$. The values of this coefficient for all zones, A-D, and the respective peak ground accelerations are as follows:

$\alpha_{\mathrm{A}}=1 ; \quad \alpha_{\mathrm{B}}=0.7 ; \quad \alpha_{\mathrm{C}}=0.5 ; \quad \alpha_{\mathrm{D}}=0.3$

$a_{g}=0.265 \mathrm{~m} / \mathrm{s}^{2} \quad a_{g}=0.186 \mathrm{~m} / \mathrm{s}^{2}$

$a_{g}=0.133 \mathrm{~m} / \mathrm{s}^{2} \quad a_{g}=0.080 \mathrm{~m} / \mathrm{s}^{2}$.

The values for the maximum tensile stress, obtained at the top of the inner walls in the longitudinal direction at the connection with the exterior walls for all seismic zones, are shown in Table 5.

\section{Discussion}

\subsection{Safety verification format}

The safety verification format is based on the comparison between design-action effects and resistance in terms of stresses. This procedure does not allow following the structure's behaviour all the way to rupture. Nonlinear dynamic analysis may provide a more realistic description of the real seismic behaviour up to rupture, yielding more reliable estimates of the ultimate seismic capacity. But this reliability depends directly on the reliability of the hysteretic models that describe the nonlinear cyclic behaviour of the materials. However, the reliability of these models for earth materials is arguable and in this situation the reliability of nonlinear dynamic models may not be guaranteed. It should also be noted that, even though exceeding the reference stresses may be only an indication of cracking, due to the brittle nature of the material localized or total collapse may be triggered shortly after cracking, reducing the extent and relevance of nonlinear behaviour.

Therefore given the facts that (i) the brittle nature of rammed earth limits the extent of nonlinear behaviour, which tends to be far below the one exhibited for instance by reinforced concrete structures, (ii) there is a deficit of reliable input for more sophisticated methodologies of analysis, and (iii) there is a need to control economic damage, that implies the limitation of cracking in the earth walls, linear elastic analysis becomes acceptable for the purpose of designing new and strengthened structures. Besides, even in the framework of linear analysis the difference between the maximum stresses and the allowable values can be considered an indicator of the extent of damage and possible collapse. In the case of non-strengthened structures, the difference between the maximum tensile stresses ( $\sigma=0.450 \mathrm{MPa}$ ) and the allowable values ( $\sigma=0.130 \mathrm{MPa}$ ) in several locations is very high and clearly indicates that damage would be extensive, eventually leading to collapse.

\subsection{Design recommendations}

The results confirm the fears that non-strengthened rammed earth construction is not suitable in zones of moderate and high seismicity. This is due to the large difference between the maximum stresses, in particular tensile stresses, and the respective acceptable values. However, the main conclusion of this work is that it is possible to built earth constructions in high seismicity areas with acceptable levels of seismic resistance, providing that adequate design and strengthening rules and solutions are observed. This conclusion allows taking advantage of this type of material, recyclable and with low energy demand for manufacture, without endangering people's lives and property.

The strengthened structures showed much lower levels of displacements and stresses in the earth elements than the non-strengthened structure. The inclusion of stone elements in the intersections of walls and around openings improved the behaviour, leading to a significant reduction of the largest out-ofplane displacements and to considerable reductions of the highest stresses. However, in some cases the maximum tensile stresses are almost twice the maximum allowable tensile stress, indicating that extensive damage may take place. The inclusion of cables connecting parallel façades was not found to be very effective in structures previously reinforced with stone elements at wall intersections and openings. However, it should be noted that a nonlinear analysis, accounting for a possible decrease in stiffness of the walls in the longitudinal direction after tensile cracking, would probably indicate that the cables are more effective at counteracting these effects by restricting the out-of-plane movement of exterior walls. Nevertheless, the results show that the most effective reinforcement strategy is adding $\mathrm{RC}$ beams at the top of all walls, and adding RC columns at all wall intersections. By restricting the earth wall deformations and confining the earth wall panels, the RC elements greatly reduce tensile stresses in the earth walls, to levels only slightly above the allowable values and below these values in the case of shear stresses. This is based on the assumption that relative displacements do not take place at the concrete-earth interfaces, which may need to be assured by specific detailing. All this indicates that earth structures may survive strong earthquakes with moderate damage if properly designed and reinforced. Another advantage of the strengthening with reinforced concrete elements is that if serious damage occurs, e.g. caused by an earthquake that induces soil acceleration above the design values, or because the material properties are worse than expected, the RC frame (beams and columns) may continue to sustain the roof. Therefore, it is recommended that the RC elements are explicitly designed to withstand the weight of the roof structure. Even though this may not be enough to control damage in the situations previously described, it will probably safeguard human life. To control damage in these situations, it may be necessary to improve the earth characteristics in order to avoid or at least contain the extent of cracking. A possible technique for this may be to mix earth with cement (stabilization). For instance, according to Galante [26], for a mix of earth with $5 \%$ cement, a compressive stress of $3.05 \mathrm{MPa}$ would be a plausible maximum value (an increase of $400 \%$ from earth without 
cement). This would lead to $\sigma_{\text {maxtens }}=0.61 \mathrm{MPa}\left(\sigma_{\text {maxtens }}=\right.$ maximum tensile strength), according to Varum's criterion. Even though the results on earth stabilization are expected, they are mentioned to highlight that damage can be avoided by treating the soil, yielding a higher quality material better able to withstand higher stresses.

Another issue that may be quite relevant in some locations, near possible epicentres, is the influence of vertical accelerations. Even though vertical accelerations were considered in the analysis, the respective peak ground accelerations, $2 / 3$ of the horizontal accelerations, are below $0.2 \mathrm{~g}$, thereby reducing the vertical compressive stresses due to own weight, but not by too much. However, near the epicentral regions vertical accelerations may be much higher than this. In these conditions, the friction resistance to shear stresses decreases and strong damage due to horizontal shear stresses becomes much more likely. This was one of the causes of the extensive damage observed in earth constructions during the Bam earthquake of December 2003. In these circumstances both types of strengthening, adding RC elements and soil improvement, may be necessary, especially if it is intended to limit the level of damage (associated with the economic losses).

All the above comments refer to well-designed constructions in high seismicity zones. As would be expected, in lower seismicity zones well designed structures undergo less stress (as seen in Table 5) and damage levels are lower, making it possible to downgrade the reinforcing solutions compared with what is proposed for high seismicity zones.

The importance of good design should be emphasized, as assumed in the study presented. Therefore, much poorer seismic performances should be expected for constructions where the design criteria referred to in point 2.1 are disregarded.

\section{Synopsis and conclusions}

This paper is a small contribution to sustainable construction, in this case in the shape of new constructions in which earth is the main structural material. Following the revival of this material for ecological reasons, constructions have been built in seismic regions without making due provision for structural safety, a potentially catastrophic situation given the well-proven limitations of the material from the point of view of resistance to cyclic actioneffects.

This study shows that a compromise between ecology and safety can be reached if earth walls are bound together by a set of RC frames (invisible from the outside), even in strong seismicity areas. Damage can be further controlled if the earth is stabilized with cement or other binders, especially bearing in mind that the mechanical properties of earth as a structural material show a very significant scatter that was not taken into account in this study.

There are many bad examples of interventions in existing earth constructions where reinforced concrete beams and slabs have been added, strongly increasing the weight of these buildings and leading to considerable damage in the event of later seismic events. The widely accepted conservation principles have also been jeopardized by some of these interventions.

What is being proposed here is something different: design rules on new (i.e. non-historical) earth construction, without affecting the traditional architecture features, hardly increasing its own weight, and making a contribution to the enhancement of buildings behaviour to seismic actions that otherwise would be extremely unsafe to live in.

\section{Acknowledgements}

Thanks are due to the FCT (Foundation for Science and Technology) for its financial support and to the ICIST - IST research centre.

\section{References}

[1] Guillaud H. Characterization of earthen materials. In: Avrami E, Guillaud $\mathrm{H}$, Hardy M, editors. Terra literature review-an overview of research in earthen architecture conservation. Los Angeles (United States): The Getty Conservation Institute; 2008. p. 21-31.

[2] Lourenço P. Earth construction: natural materials as a contribute to construction sustainability (Construções em terra: os materiais naturais com contributo à sustentabilidade na construção). Master thesis in construction. Technical University of Lisbon; 2002 [in Portuguese].

[3] NZ 4297. Engineering design of earth buildings. New Zealand: Earth Building Association of New Zealand; 1998.

[4] New Mexico Earthen Building Materials Code 14.7.4. Santa Fé (NM): Construction Industries Division (CID) of the Regulation and Licensing Department; 2006.

[5] The Australian earth building handbook. Sydney (Australia): Standards Australia; 2002.

[6] Gomes I. Seism-resistant rammed earth construction (Construção sismoresistente em terra crua). Master thesis in construction. Technical University of Lisbon; 2008 [in Portuguese].

[7] Jaquin PA, Augarde CE, Gerrard C. Analysis of historic rammed earth construction. India: Structural Analysis of Historical Constructions in New Delhi; 2006.

[8] Augarde CE, Jaquin PA, Gerrard CM. Analysis of Tapial structures for modern use and conservation. Padua (Italy): Structural Analysis of Historical Constructions; 2004.

[9] Maniatidis V, Walker P. Structural capacity of rammed earth in compression. J Mater Civ Eng 2008;20(3):230-8.

[10] Hall M, Djerbib Y. Rammed earth sample production: context, recommendations and consistency. Constr Build Mater 2004;18:281-6.

[11] Jayasinghe C, Kamaladasa N. Compressive strength characteristics of cement stabilized rammed earth walls. Constr Build Mater 2007;21:1971-6.

[12] Morel JC, Pkla A, Walker P. Compressive strength testing of compressed earth blocks. Constr Build Mater 2007;21:303-9.

[13] Jayasinghe C, Mallawaarachchi SR. Flexural strength of compresses stabilized earth masonry materials. Mater Des 2009;30:3859-68.

[14] Coburn A, Hughes R, Pomonis A, Spence R. Technical principles building for safety. London (UK): Intermediate Technology Publications; 1995.

[15] Blondet M, García G, Loaiza C. Earthquake resistant construction of dwellings? A vision for the future (Viviendas sismorresistentes de tierra? Una visión a futuro). In: XIV national congress of civil engineering-CONIC. 2003 [in Spanish]

[16] Peña F, Lourenço P. In: M. Achenza et al., editors. Earth structures: behaviour and pathologies. Houses and cities built with earth. Conservation, significance and urban quality. Argumentum; 2006. p. 49-51.

[17] Ministerio de Vivienda Y Construcción. Adobe-design and construction (Adobe - Diseño y construcción). Peru; 1979 [in Spanish].

[18] Martins F, Costa A, Sousa J. Three-dimensional analysis of a tunnel built in residual granite soil at University of Minho (Análise tridimensional de um túnel aberto num maciço de solo residual degranito da Universidade do Minho). In: 1st Brazilian congress on tunnels and underground structures. 2004 [in Portuguese].

[19] Varum H, Martins T, Velosa A. Characterization of adobe construction in the Aveiro region. In: IV Ibero-American earth construction seminar and III seminar of earth construction architecture in Portugal. 2005.

[20] RSA. Portuguese loads code for structural safety of buildings and bridges. (Regulamento de segurança e acções em estruturas de edifícios e pontes). Lisbon (Portugal); 1983 [in Portuguese].

[21] SAP2000 ${ }^{\circledR}$. Three dimensional static and dynamic finite element analysis and design of structures. Version 8.3.0. Berkeley (CA, USA): CSI Computers \& Structures, Inc., Structural and Earthquake Engineering Software. 2004.

[22] Blondet M, Garcia G, Brezv S. Earthquake resistant adobe construction (Construcciones de adobe resistentes a los terremotos: tutor) contribution to the World Housing Encyclopaedia. Oakland (CA): Earthquake Engineering Research Institute, EERI; 2003 [in Spanish]. www.world-housing.net.

[23] Parreira D. Seismic analysis of rammed earth construction, (Análise sísmica de uma construção em taipa). M.Sc. thesis. Lisbon: IST; 1987 [in Portuguese].

[24] Zegarra L, Quiun D, San Bartolomé A. Strengthening techniques for adobe dwellings (Técnicas para el reforzamiento sísmico de viviendas de adobe). In: XIV national congress of civil engineering. 2003 [in Spanish].

[25] Pinto M, Payalich E, Wamsler C. Reconstruction project with risk management-technical elements and institutional strategy to reduce risk and the dimension of future disasters (Proyecto de reconstrucción con inclusión de la gestión de riesgo-elementos técnicos y estrategia institucional para la disminución del riesgo y de la dimensión de futuros desastres). División 4200, Democracia y Gobernabilidad. Deutsche Gesellschaft für Technische Zusammenarbeit (GTZ) GmbH. Eschborn (Peru); 2003 [in Spanish].

[26] Galante R. Rammed earth construction and recycling of materials (A construção em taipa e a reciclagem de materiais). Graduation report in architecture. Technical University of Lisbon; 2004 [in Portuguese]. 